\title{
A Main Performer May Come for Percutaneous Coronary Intervention With Atrial Fibrillation in Japanese Patients
}

\author{
Ken Kozuma, MD, PhD
}

$\mathbf{P}$ ercutaneous coronary intervention (PCI) plays a leading role in the treatment of coronary artery disease (CAD). PCI always requires dual periprocedural antithrombotic agents (so-called DAPT [dual antiplatelet therapy]) to avoid coronary events such as stent thrombosis (ST) and myocardial infarction (MI). Historically, rates of ST while using aspirin and warfarin were around $3 \%$, and DAPT decreased this to less than $1 \%{ }^{1}$ Therefore, the concept that anticoagulation is inappropriate for the prevention of ST was established among cardiologists at the time of coronary stent introduction. Recently, the risk of ST has been dramatically decreased with the use of newer generation drug-eluting stents. ${ }^{2}$ However, it is still common knowledge that ST and periprocedural MI mostly occur on the first day of PCI. ${ }^{3}$ In this regard, the rapid

\section{Article p 1000}

effect of antiplatelet agents is important to further improve the outcome of PCI. Prasugrel is a newer generation $\mathrm{P}_{2} \mathrm{Y}_{12}$ receptor antagonist that has faster metabolism after intake and lower inter-individual variability in platelet response than clopidogrel. Prasugrel was shown to reduce ischemic events but to increase bleeding complications in the TRITON TIMI-38 trial. ${ }^{4}$ Prudent dose adjustment has been performed for its introduction to the Japanese patients. Pivotal trials such as Prasfit ACS $^{5}$ and Prasfit elective ${ }^{6}$ for Japanese approval demonstrated equivalent incidence of bleeding complications and lower incidence of periprocedural MI than with clopidogrel. A dose of $3.75 \mathrm{mg}$ daily is

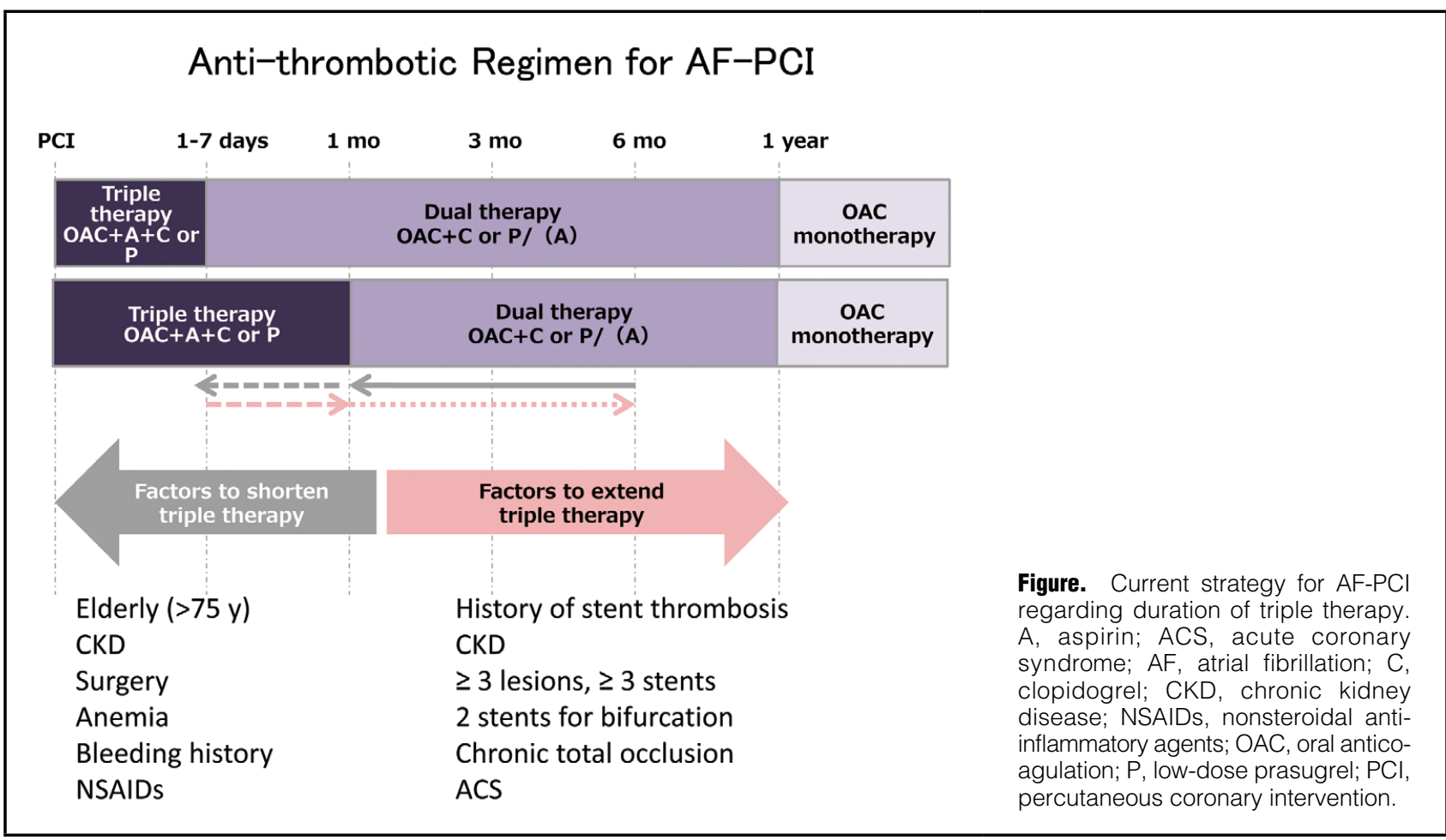

The opinions expressed in this article are not necessarily those of the editors or of the Japanese Circulation Society.

Received March 4, 2019; accepted March 8, 2019; J-STAGE Advance Publication released online March 27, 2019

Division of Cardiology, Department of Internal Medicine, Teikyo University School of Medicine, Tokyo, Japan

Mailing address: Ken Kozuma, MD, PhD, Division of Cardiology, Department of Internal Medicine, Teikyo University School of Medicine, 2-11-1 Kaga, Itabashi-ku, Tokyo 173-8605, Japan. E-mail: PXE00364@nifty.com

ISSN-1346-9843 All rights are reserved to the Japanese Circulation Society. For permissions, please e-mail: cj@j-circ.or.jp 
almost one-third of global dose without any increase in either thrombotic or bleeding complications in a real-world registry. ${ }^{7}$ Therefore, a kind of evidence lag between foreign countries and Japan has occurred in the antithrombotic medical field, because no global trial includes a $3.75-\mathrm{mg}$ dose of prasugrel.

Atrial fibrillation (AF) is one of the most common diseases in the cardiovascular field. It requires oral anticoagulant therapy (OAC) for the prevention of thromboembolism. The effect of DAPT for stroke prevention in AF patients was demonstrated to be lower than that of warfarin in a large randomized trial. ${ }^{\mathbf{8}}$ Therefore, both antiplatelet and anticoagulation agents were thought to be necessary for AF patients undergoing PCI according to the guidelines of CAD and AF. Several randomized trials have demonstrated the mistake of combination strategy using aspirin, clopidogrel, and warfarin/DOAC, so-called "triple therapy". The European guideline on DAPT in CAD changed the recommendation in 2017. ${ }^{9}$ Now, triple therapy should be as short as possible. Dual therapy with clopidogrel and OAC is recommended up to 1 year after PCI rather than triple therapy, as demonstrated in the meta-analysis. ${ }^{10}$ The current standard regimen of antithrombotic therapy for patients with AF undergoing PCI (AF-PCI) emphasizes the importance of dose adjustment according to the patient's risk for bleeding and thrombosis (Figure).

Thus, the question remaining is whether we can use lowdose prasugrel for Japanese patients with AF-PCI. Because carriers of $\mathrm{CYP}_{2} \mathrm{C}_{19}$ reduced-function alleles have been shown to be associated with ST and cardiovascular events because of their poor metabolism of clopidogrel after PCI,11 there is a concern of thrombotic complications regarding the "skip aspirin" strategy, especially in East Asia. Outside Japan, a 10-mg dose of prasugrel has been categorized as a contraindication with concomitant use of OAC because of the high bleeding risk. In this issue of the Journal, Otsuki et $\mathrm{a}^{12}$ focus on low-dose prasugrel use after PCI using DES compared with clopidogrel as part of triple therapy. This is an important message for interventional cardiologists who hesitate to stop aspirin for fear of ST caused by reduced effect of clopidogrel monotherapy. As previously stated, there were no benefits and more bleeding complications with triple therapy as compared with dual therapy. The use of low-dose prasugrel is anticipated as the appropriate choice for dual therapy in Japan. However, prospective randomized clinical trials for off-label use are difficult to perform because of the different doses used in other countries, as previously described. Furthermore, a new law on clinical research has come into force in Japan. We need large amounts of accumulated observational data to overcome these difficulties for Japanese patients. Otsuki et al are describing a local but very important issue, ${ }^{12}$ and it is the beginning of the story.

\section{Conflict of Interest}

The author has received remuneration from Sanofi, Daiichi-Sankyo, Bayer, and Boehringer Ingelheim.

\section{References}

1. Leon MB, Baim DS, Popma JJ, Gordon PC, Cutlip DE, Ho KK, et al. A clinical trial comparing three antithrombotic-drug regimens after coronary-artery stenting: Stent Anticoagulation Restenosis Study Investigators. N Engl J Med 1998; 339: $1665-$ 1671.

2. Tada T, Byrne RA, Simunovic I, King LA, Cassese S, Joner M, et al. Risk of stent thrombosis among bare-metal stents, firstgeneration drug-eluting stents, and second-generation drugeluting stents: Results from a registry of 18,334 patients. JACC Cardiovasc Interv 2013; 6: 1267-1274.

3. Nakamura M, Yamagishi M, Ueno T, Hara K, Ishiwata S, Itoh $\mathrm{T}$, et al. Current antiplatelet therapy for Japanese patients with ST elevation acute myocardial infarction: J-AMI registry. Cardiovasc Interv Ther 2013; 28: $162-169$.

4. Wiviott SD, Braunwald E, McCabe CH, Montalescot G, Ruzyllo W, Gottlieb S, et al. Prasugrel versus clopidogrel in patients with acute coronary syndromes. N Engl J Med 2007; 357: 2001-2015.

5. Saito S, Isshiki T, Kimura T, Ogawa H, Yokoi H, Nanto S, et al. Efficacy and safety of adjusted-dose prasugrel compared with clopidogrel in Japanese patients with acute coronary syndrome: The PRASFIT-ACS study. Circ J 2014; 78: 1684-1692.

6. Isshiki T, Kimura T, Ogawa H, Yokoi H, Nanto S, Takayama $\mathrm{M}$, et al. Prasugrel, a third-generation $\mathrm{P}_{2} \mathrm{Y}_{12}$ receptor antagonist, in patients with coronary artery disease undergoing elective percutaneous coronary intervention. Circ J 2014; 78: 2926-2934.

7. Nakamura M, Kozuma K, Kitazono T, Iizuka T, Sekine T, Shiosakai K, et al. Prasugrel for Japanese patients with ischemic heart disease in long-term clinical practice (PRASFIT-Practice II): A 3-month interim analysis of a postmarketing observational study. Circ J 2019; 83: 637-646.

8. Connolly S, Pogue J, Hart R, Pfeffer M, Hohnloser S, Chrolavicius S, et al. Clopidogrel plus aspirin versus oral anticoagulation for atrial fibrillation in the Atrial fibrillation Clopidogrel Trial with Irbesartan for prevention of Vascular Events (ACTIVE W): A randomised controlled trial. Lancet 2006; 367: $1903-1912$.

9. Valgimigli M, Bueno H, Byrne RA, Collet JP, Costa F, Jeppsson A, et al. 2017 ESC focused update on dual antiplatelet therapy in coronary artery disease developed in collaboration with EACTS: The Task Force for dual antiplatelet therapy in coronary artery disease of the European Society of Cardiology (ESC) and of the European Association for Cardio-Thoracic Surgery (EACTS). Eur Heart J 2018; 39: 213-260.

10. Golwala HB, Cannon CP, Steg PG, Doros G, Qamar A, Ellis $\mathrm{SG}$, et al. Safety and efficacy of dual vs. triple antithrombotic therapy in patients with atrial fibrillation following percutaneous coronary intervention: A systematic review and meta-analysis of randomized clinical trials. Eur Heart J 2018; 39: 1726-1735a

11. Sorich MJ, Rowland A, McKinnon RA, Wiese MD. CYP2C19 genotype has a greater effect on adverse cardiovascular outcomes following percutaneous coronary intervention and in Asian populations treated with clopidogrel: A meta-analysis. Circ Cardiovasc Genet 2014; 7: 895-902.

12. Otsuki H, Yamaguchi J, Kawamoto T, Yoshikawa M, Ebihara S, Tanaka K, et al. Safety and efficacy of low-dose prasugrel as part of triple therapy with aspirin and oral anticoagulants in patients with atrial fibrillation undergoing percutaneous coronary intervention: From TWMU-AF PCI Registry. Circ J 2019; 83: $1000-1005$ 